\title{
The Research on the Way out of Chinese Traditional Media in Big Data
}

\author{
Shuang WEI \\ Center for Digital Media and Culture, UESTC, School of Politics and Public Administration of \\ UESTC, Chengtu, China \\ 361269693@qq.com
}

Keywords: Big Data ,Chinese Traditional Traditional ,the Way out.

\begin{abstract}
Since the beginning of 2013, with the popularity of mobile Internet, the use of things, the promotion of cloud computing technology, the arrival of Chinese Traditional Media in the era ofbig data in the face of an unprecedented survival crisis, but also some of the Chinese Traditional Media takebig data of the wind This paper is based on the dilution of the right of the Chinese Traditional Media media, the weakening of the media agenda, the lack of talent structure, the lack of compound talents, the realistic dilemma of the decline of the audience and the decline of loyalty. News gatekeeper, promote media integration, strengthen the visualization of news expression, cultivate professional compound talents 5 levels, to explore the era of large media under the Chinese Traditional Media.
\end{abstract}

\section{Introduction}

In 2002, Victor Meyer Schoenberg and Kenneth Cookey put forward the "big data" concept in the Big Data Age article. It is pointed out that the big data is based on the data mining on the basis of all the data on a particular area for analysis and processing. big data age is a large-scale production, analysis and processing of application data of the times. The advent of the era of big data, the impact of traditional journalism bear the brunt of the impact. As Chris Anderson puts it, journalism is the first industry to really feel the impact of the Internet. In his view, the traditional journalism in the past spread in the pattern of absolute leadership, they have a monopoly on the news, and traditional journalism is now facing a big data era brought about the "disaster." With the arrival of the era of big data, media people must re-understand the media's living environment to examine the essence of the media content. With the popularity of mobile Internet, the use of things, the promotion of cloud computing technology, the arrival of Chinese Traditional Media in the era ofbig data is facing an unprecedented survival crisis.

In 2015,The Morning Post, City Weekly and Jiujiang Morning News, the three paper media have been published out of the publication announcement, announced that in 2016 will stop the paper version of the publication of newspaper publications, will have fought in the new media camp. In the era of big data, the Chinese Traditional Media is faced with problems such as poor news timeliness, lack of audience, reduced loyalty, lack of talent structure, lack of strategy and strategic transformation. In contrast, social media by virtue of their own technical advantages to move closer to big data, to adapt to the era of big data core media. While the Chinese Traditional Media in the era of large-scale media to reduce the influence of media, media right to be diluted, the media living space was squeezed, faced with unprecedented difficulties in survival. Big data age, the transformation of Chinese Traditional Media is imperative.

\section{The Predicament of Chinese Traditional Media in the Big Data}

\section{Dilute Media Discourse and Weak Media Agenda}

In the context of the big data era, the rise of the social media, which is different from the Chinese Traditional Media decisions of the audience and the microblogging microblogging, has made the Chinese Traditional Media's discourse right diluted, and the Chinese Traditional Media has lost its central position in the media The Chinese Traditional Media on the news production and 
dissemination of the monopoly in the era of big data is broken, the news production is no longer attached to the original hierarchical transmission pattern. In the era of big data, UGC (User Generated Content) came into being, the user will own the original news content through the two micro-end of their own personal experience of the news events to show in the social media caused widespread concern and discussion, to attract the audience's attention The These modes of production and transmission are completely different from the Chinese Traditional Media social media, with the Chinese Traditional Media for the audience market. dilute the influence of Chinese Traditional Media, in this case, the Chinese Traditional Media produced by the limited news resources are buried in the "information Explosion "of the social media production of big data, making the audience on the Chinese Traditional Media attention fell sharply. The audience to rely on Chinese Traditional Media to carry out the interpretation of the absolute pattern of information is broken, in the social media to form a huge network of information, the Chinese Traditional Media provided by the news information is weakened. Rio in the process of reporting the Olympic Games to CCTV as the representative of the traditional television media trying to "Rio Olympics" as the audience news agenda first, but at 14:21 on August 14, actor Baoqiang Wang published in the microblogging platform "divorce Statement ", said Rong Ma and his agent Zhe Song occurred outside the improper relationship. "Baoqiang Wang divorce" that night to become the first real-time hot search list, the night Baoqiang Wang divorce reading as high as 1.29 billion. For several days to become the audience to discuss the topic, its concern is much higher than the Rio Olympic related topics.

\section{Talent Structure is Single and Lack of Compound Talents}

In the era of big data, the new news production model, represented by data news, came into being. Data news was a new form of reporting with the press on behalf of the data, and the data news also reflected the fact that data technology News industry full penetration of the impact of the status quo, this new way of news production, the Chinese Traditional Media among the training of journalists raised the challenge. In the era of big data, the new news production model, represented by data news, came into being. Data news was a new form of reporting with the press on behalf of the data, and the data news also reflected the fact that data technology News industry full penetration of the impact of the status quo, this new way of news production, the Chinese Traditional Media among the training of journalists raised the challenge. In the traditional press conference, journalists, editors and artists constitute the production chain of traditional news. The journalists are responsible for producing news and editors to judge whether the news is valuable, and the art workers are responsible for news publishing and aesthetics. The requirements for the production team are too weak.

"Data Visualization" website blogger Andy Kirk once wrote data visualization of the eight hat, from a project point of view describes the entire data visualization team included in the role, as well as the role of their own way of thinking. The eight roles are: decision makers, data scientists, journalists, computer scientists, designers, cognitive scientists, negotiators, project managers. While the Chinese Traditional Media only specializes in editing and editing of the editorial and visualization of the art design and decision-making status of the editor, the lack of data scientists and programmers and other professionals and information collection and analysis of the ability to deal with technology professional talents.

\section{Audience Stickiness is Reducing and Loyalty Droping}

The development of smart phones, the popularity of mobile terminals, to build a decentralized communication model, breaking the Chinese Traditional Media transmission privileges. As the audience in the social media access to news and news events occur almost simultaneously, the social media news timeliness so that the Chinese Traditional Media look back, the audience only need to use smart phones, you can anywhere in the mobile terminal to browse information, to understand the latest news events Dynamic, to meet the needs of news and information, no longer rely on television and other regular publications such as newspapers and periodicals to get news, while the interaction of new media to give the audience an unprecedented sense of participation, 
especially UGC. Users can not only use the social media the first time instead of journalists on-site coverage, but also free to comment, exchange views. In contrast, the Chinese Traditional Media news timeliness is poor, and the audience interaction is poor, leading to low viscosity and decreased loyalty.

\section{The Countermeasure of Chinese Traditional Media 's Response to Predicament in the Big Data Age}

\section{Using the New Media Platform to Improve the News Timeliness}

Timeliness is the basic requirement of news reporting. Fast spread, not only to win the audience, for the initiative, but also enhance the dissemination of news effect. In news communication, "time" is usually reflected in the "timeliness". It emphasizes the report of the recent facts. In the context of big data, the changes in the "time" of the news show some new features. The connotation of "time" is more embodied as "full time" and "immediacy". The social media represented by microblogging in the era of big data is characterized by its speed of communication and the speed of split transmission, and its news timeliness is almost synchronized with the incident. Coupled with the advantages of social media itself with the help of mobile terminals, making its news release will be widespread concern, reducing the Chinese Traditional Media news influence. Chinese Traditional Media can enhance the timeliness of its press release with two micro-end platforms.

This requires journalists to spread of the information what the reader is most concerned about with the fastest speed and improve the news timeliness. Even with the new media platform in the two micro-one on the news events "live webcast" to achieve the news release and event synchronization, in order to improve the news timeliness. Such as the Chinese Traditional Media: Chengdu Business Daily in the microblogging platform to create "Shangmei live" topic, occurred in Chengdu, some important news events using microblogging platform for live webcast, on December 2, its release of a news " Rock poet Zheng Jun for the original music sound, awarded millions of awards to encourage the original musicians on the use of a network of live way for the audience to convey information, improve the timeliness of the news.

\section{Strengthening the News Gatekeeper}

In the context of the great data age, the rise of new media and the emergence of citizen news make news and information communication more and more convenient. At the same time, many false news will follow, and the role of news gatekeeper is big Era, the Chinese Traditional Media and other new media compared to an advantage is also an unshirkable responsibility, the Chinese Traditional Media in the press release of the authority is to win the majority of the audience a trump card, it must strengthen the news gatekeeper. First of all, the Chinese Traditional Media must be in the pursuit of news on the premise of ensuring the authenticity of the news. Really is the life of the news.

The era of big data, the new media-based social media platform simplifies the process of communication, so that information directly from the communicator passed to the audience, news greatly improved. The audience's own media literacy varies greatly, if not at the source to live really off, then the fake news will be in the social media separation of the spread of the pattern of baseless assertions, out of control, bring serious social impact. Chinese Traditional Media must spread the news and information to strictly control, to prevent false news. Second, the Chinese Traditional Media in the event of major news events have their unique advantages of public opinion, online audiences can be appropriate guidance of public opinion, which requires the Chinese Traditional Media in the reference to the new media information published when the truth insisted on the truth, News processing, so that the audience's public opinion to lead to rational, to avoid the occurrence of cluster effect.

\section{Promoting Media Integration}

Professor Pauer of the Massachusetts Institute of Technology in the United States first proposed the 
concept of media convergence (Media Convergence). In the view of Professor Bohr, media integration is a trend of multi-functional integration of various media, andChinese Traditional Media such as television and newspaper broadcasting are integrated with new media platforms. Compared with the new media, Chinese Traditional Media has a certain comparative advantage in the aspects of content editing and editing. In the course of promoting the strategic transformation of Chinese Traditional Media, the Chinese Traditional Media should make full use of the advantages of Chinese Traditional Media content, the main content quality, The media's high-quality content reported digital visual processing, relying on new media communication channels with a new way of reporting news. Zhejiang Daily Group in the process of media integration to achieve the main news information, digital entertainment and intelligent service three main lines, in the new media platform for vertical and regional "news + service" strategic exploration. To create a "Zhejiang News" mobile client, the new version of Zhejiang Mobile newspaper, Zhejiang online news sites and video news as the core circle of the authority of the new media platform in Zhejiang, while the winger network news area and news bulletin, cloud read PAD client, Winger Internet TV box, money newspaper network, Tencent Zhejiang news area and the county (city, district) domain portal for the close circle of the mainstream news communication platform to the operating media more than 200 microblogging, WeChat and other third-party network applications And professional APP for the collaborative circle of the mainstream value of the dissemination platform.

\section{Strengthening the Visualization of News}

In the trend of fast food reading, the traditional news to the text-based way of reporting will make readers have lost reading interest in reading fatigue, in the reading time, the Chinese Traditional Media can be reported to the news information visual visualization refers to the computer graphics and Image processing technology is based on the premise of data mining under the premise of the data into a vivid graphics or animation graphics, news communication field of visualization is more representative of the data news, in the production of news in the process of using a variety of Information chart data map time axis and other specific and objective way to be presented to the news information to convey to the audience. In the Big data age ,audience fast-paced life more performance in the mobile phone brush news is a mechanical fast browsing, in the fast-food reading trend, the traditional news to the text-based way of reporting will make readers tired of reading loss of reading interest in reading In the era of the times, the traditional media can visualize the news information to be reported, and use the vivid chart form to more intuitively and vividly reflect the process and development trend of the news event, and can attract the reader's interest in reading. In particular, the production of data news to meet the fast-food reading era of readers to receive information needs.

For example, the data news of Beijing News on May 1, 2014 ,"Chinese leaders of the African footprints" ,to cleverly dismantle the African map, and our leaders to Africa, the specific circumstances of the combination of clever leadership People have been to the city of Africa and the number of times each city to conduct a detailed summary, and listed on the map to reach the leaders of each city, this visualization of the way the reader in the intuitive image of the specific news visual expression, Through the chart and data on the diplomatic relations between China and Africa have a more like to the sister, this through the collection of massive data, data mining and visual performance of the news coverage intuitive and clear and more in line with the reader's reading needs, to provide readers with more Good reading experience.

\section{Cultivating Professional Compound Talents}

"Data Visualization" website blogger Andy Kirk once wrote "data visualization of the eight hat", from a project point of view describes the entire data visualization team included in the role, as well as the role of their own way of thinking. The eight roles are: decision makers, data scientists, journalists, computer scientists, designers, cognitive scientists, negotiators, project managers. In the era of big data, the Chinese Traditional Media must break through the talent structure of the professional talents, edit the talent structure with the editor of the editors, and cultivate a variety of professional talents, especially the data analysis scientists and data visualization designers. The 
news reports to be more professional and more technical.

\section{Summary}

In the era of big data, if the Chinese Traditional Media wants to achieve the goal of "self-breakthrough" in the current situation of the rise of new media, it is necessary to find out the advantages and make use of the Internet data in the process of strategic transformation. Platform, keep up with the audience's reading needs, and actively use advanced communication technology.

\section{Acknowledgement}

This research was financially supported by the National Science Foundation.

\section{References}

[1] Pu Ying-Hung et a.The design and implementation of a mobile library App system.,J.Library Hi Tech,2015.

[2]Hurley.K.Think like a data journalist.,J.The Guardian , 2012.

[3] Fang Jie, Yan Dong.News in the global perspective: ideas and practice , J. International press. 2013 .

[4] Rogers,S. Data journalism at the Guardian:what is it and how do we do it, J.The Guardian . 2011.

[5] Chen Li Dan, Li Yiqi, Na Jia,Large data and news reports ,J.Journalists. 2015.

[6] Chen, JP, Feng, S., Liu, J.Topic sense induction from social tags based on nonnegative matrix factorization, ,J.Information Sciences,2014.

[7] Marijan, Robert and Leskovar, Robert.A library’s information retrieval system (In)effectiveness: case study, ,J.Library Hi Tech. 2015.

[8] Jin Yi and Peng Jia. Information portal development and practice at Shanghai Jiao Tong University Library, ,J.Online Information Review.2012.

[9] Pisanski, J. and Zumber, M.National library web sites in Europe: an analysis, Program: Electronic library and information systems,2005.

[10] Joorabchi, Arash, Mahdi, Abdulhussain E. Towards Linking Libraries and Wikipedia: Automatic Sybject Indexing of Library Records with Wikipedia Concepts, ,J.Journal of Information Science,2014.

[11] Gairin-Rodrigues, Josep-Manuel and Marta Somoza-Fernandez.Web services to link interlibrary software with OCLC World Share, ,J. Library Hi Tech, 2014.

[12]Information o http://vislab.caixin.com/ 